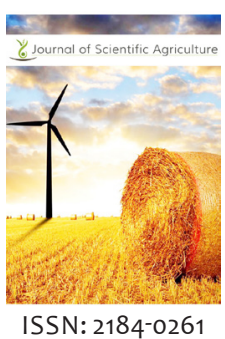

Received: May 29, 2020 Accepted: July 28, 2020 Published: August 10, 2020

*Corresponding Author: Wilfred Abincha Email:wilabin@yahoo.com

\section{Flowering problems and their possible solution in cassava breeding}

\author{
Yasmin Ibrahim', Yona Baguma², Wilfred Abincha1,3*, Paul Gibson', \\ Richard Edema' and Jenipher Bisikwa'
}

'Makerere University P.O Box 7062, Kampala, Uganda, ${ }^{2}$ National Crops Reseource Research Institute P.O. Box 7084, Kampala, Uganda, ${ }^{3}$ Mount Kenya University, P.O Box 4441, Kisii, Kenya

\begin{abstract}
Six elite cassava clones were chosen from cassava breeding program at the National Crops Resource Research Institute (NaCRRI) based on their flowering characteristics and seed set. The clones were planted in randomized complete block experimental design with 3 replications. The floral biology of these cassava clones were studied, focusing on morphological traits and developmental timing. Since cassava develops branches in levels, data was sourced from the $1^{\text {st }}$ level of branching through the $4^{\text {th }}$ level of branching. The result indicated that days to branching generally varied among all the genotypes studied, indicating the need to use different planting dates for different genotypes to ensure synchronization of flowering. The time difference among genotypes from branching to visible inflorescence was not larger than one and a half days and this difference did not seem be a factor for synchronization. The general number of female flowers was low in all genotypes across branching levels. This suggests there is a need to apply techniques that could enhance flowering in cassava. Conversely, the number of male flowers outnumbered the female flowers, suggesting that male flower production may not be a limiting factor to hybrid seed production. Male flower opened 20 to 30 days later after the opening of the female flowers. This calls for delayed planting of the early flowering genotypes when used as female parent. It was recommended that in order to synchronize flowering, the late flowering genotypes have to be planted ahead of the early flowering genotypes. In addition, applying techniques such as growth regulators, red light and finding the most optimal locations for flowering is recommended for further study as a way of enhancing flowering among cassava genotypes.
\end{abstract}

KEYWORDS: Cassava, flowering, synchronization, breeding

\section{INTRODUCTION}

Cassava (Manihot esculenta Crantz) originated from Central Brazil with its large number of wild Manihot species [1] and subsequently distributed to tropical and subtropical Africa and Asia. Indeed, cassava is a major crop of the tropics. It is a starchy root crop used for human consumption and animal feeds and thus, cassava has become an ideal food security crop in sub-Saharan Africa where hunger is a menace [2]. The crop is consumed daily by more than 800 million people [3]. Excitingly, cassava can tolerate drought stress, and is also able to grow and produce on degraded soils where other crops do not grow well [4]. In Africa, cassava is grown mainly for human consumption, while in Asia and Latin America it is grown for food, feed and industrial purposes such as ethanol processing. As food, cassava is consumed in different forms, cooked, fried and processed in form of flour for meal [5]. The root consists of $20-30 \%$ starch, $62 \%$ water, $2 \%$ protein, $1-2 \%$ fibre, trace of vitamins and minerals [6]. The crop is grown mainly for the root which contains high amount of carbohydrate; $40 \%$ higher than rice and 25\% more than maize [7]. The leaves of cassava are also consumed as vegetable [8]. It is these benefits that have made cassava popular among resource poor communities that solely depend on this crop. On this premise, there is a global effort in research institutions for genetic improvement of this crop through plant breeding strategies.

Cassava is propagated by stem cuttings commonly practiced by farmers. Sadly, this method of propagation favours accumulation of viral and bacterial diseases over time. Often, cultivated cassava varieties do not possess all the desired agronomic traits. This has created the need to make crosses in order to develop varieties that combine desirable traits present in selected parents into one genetic background. Because cassava is a heterozygous crop, seed do not reproduce the mother plant. Crossing and seed propagation is used by breeders for the purpose of improving cassava, but it is often difficult to make the desired crosses. This is due to low seed set which results from poor flowering, non-synchronization

Copyright: ๑) The authors. This article is open access and licensed under the terms of the Creative Commons Attribution License (http://creativecommons.org/licenses/by/4.0/) which permits unrestricted, use, distribution and reproduction in any medium, or format for any purpose, even commercially provided the work is properly cited. Attribution - You must give appropriate credit, provide a link to the license, and indicate if changes were made. 
of flowering period, low pollen viability and crossing incompatibility between genotypes.

It has been found that flower production in cassava is very sensitive to environmental factors which include moisture, soil fertility, photoperiod and temperature [9]. A particular genotype may not produce flowers in one environment, but may produce aborted flowers or abundant flowers and set seeds in another environment [10]. Similarly, the availability of flowers is influenced by plant habit, because an inflorescence is always formed when branching occurs $[11,12]$. It follows that the level and timing of branching influences flower availability and fertility.

Indeed, cassava genetic improvement is constrained by most varieties which have unique useful characteristics but are difficult to cross. One of the barriers to crossing is poor flowering ability in these cassava genotypes. Indeed, some genotypes have never been known to flower [13]. Similarly, the male and female flowering time often do not synchronize well and thus, synchronization of flowering in cassava breeding has been a difficult issue [14]. The timing of flowering is one of the major factors that are of great concern to breeders since flowering can occur at very different times in different varieties. Details of timing of male and female flowering for important varieties in Uganda are not well known among genotypes. Therefore, synchronization of flowering in cassava breeding has been a difficult issue [14].

Currently in Uganda, none of the cultivated cassava cultivars (landraces and improved cultivars) possesses all the desired agronomic traits. There is need to hybridize cultivars that would combine desirable traits present in selected parents into one genetic background. Developing cultivars superior to current cultivated cassava for most economically important traits including increased nutrients, pest and diseases tolerance is an important focus of cassava breeding. Sadly, little is known about flowering in cassava [13] and therefore, a clear understanding of the reproductive biology of cassava is needed to design improved production systems among specific genotypes.

In conventional breeding, it is crucial for the breeder to be familiar with the flowering and other reproductive characteristics of complementary parents. Understanding the timing of male and female flowering in selected cassava clones will help to synchronize planting and crossing the parents. Similarly, knowledge about flowering capacity is important in order to select a group of materials with synchronized flowering [4]. This research is driven towards addressing these flowering problems that cassava breeders are facing particularly in Uganda.

\section{MATERIALS AND METHODS}

\section{Plant Materials}

Six cassava clones used in this study were obtained from the cassava breeding program at National Crops Resource Research
Institute (NaCRRI), Uganda and were chosen based on their flowering characteristics and seed set (Table 1).

\section{Experimental Design}

The six cassava clones were planted in randomized complete block design with 3 replication in a plot size of 6 meters by 5 meters. The plot contained six rows each with five plants in spacing of 1 meter between and within rows. The experiment was conducted under field condition for one season, weeding was done regularly to keep the field clean at all time and no fertilizer was applied.

\section{Data Collection}

Data was collected on a number of morphological traits (Figure 1) on daily basis. The focal morphological traits adopted for this study are shown in Table 2 .

\section{Data Analysis}

All data collected were subjected to analysis of variance (ANOVA) using GenStat $12^{\text {th }}$ edition (VSN International) to obtain mean squares of the genotypes evaluated. Means were separated using Fisher's protected least significant difference (LSD) test at 5\% level of significance.

Table 1: Selected cassava clones and their characteristics

\begin{tabular}{|c|c|c|}
\hline Clone & Pedigree & Characteristics \\
\hline NASE2 & TMS/ 30337 & High flowering and no seed set \\
\hline NASE9 & 58308 X OYARUGBADUDU & $\begin{array}{l}\text { Poor flowering and poor seed } \\
\text { set }\end{array}$ \\
\hline TME204 & Landrace & $\begin{array}{l}\text { Poor flowering and poor seed } \\
\text { set }\end{array}$ \\
\hline NASEI2 & MH95/0414 & $\begin{array}{l}\text { High flowering and high seed } \\
\text { set }\end{array}$ \\
\hline NASE14 & M M96/4271 & $\begin{array}{l}\text { High flowering and high seed } \\
\text { set }\end{array}$ \\
\hline NASE3 & TMS/30572 & $\begin{array}{l}\text { High flowering and high seed } \\
\text { set }\end{array}$ \\
\hline
\end{tabular}

Table 2: Description of morphological traits in this study

\begin{tabular}{|c|c|c|}
\hline $\mathrm{S} / \mathrm{N}$ & Traits & Description \\
\hline 1 & $\begin{array}{l}\text { Number of days to } \\
\text { branching }\end{array}$ & $\begin{array}{l}\text { The first day a forking is observed on a } \\
\text { plant, and the counting is taken at different } \\
\text { branching levels. }\end{array}$ \\
\hline 2 & $\begin{array}{l}\text { Number of days to } \\
\text { visible inflorescence }\end{array}$ & $\begin{array}{l}\text { When appearance of buds is first observed } \\
\text { after branching. }\end{array}$ \\
\hline 3 & Branching habit & $\begin{array}{l}\text { Dichotomous }=2 \text { branching habit; } \\
\text { Trichotomous }=3 \text { branching habit; } \\
\text { Tetrachotomous }=4 \text { branching habit. }\end{array}$ \\
\hline 4 & $\begin{array}{l}\text { Number of days to } \\
\text { male flower open }\end{array}$ & $\begin{array}{l}\text { The first day the male flower opens, counting } \\
\text { taken on different branching levels after } \\
\text { branching. }\end{array}$ \\
\hline 5 & $\begin{array}{l}\text { Number of days to } \\
\text { first female flower } \\
\text { open }\end{array}$ & $\begin{array}{l}\text { The first day the female flower opens, } \\
\text { counting taken on different branching levels } \\
\text { after branching. }\end{array}$ \\
\hline 6 & $\begin{array}{l}\text { Number of female } \\
\text { flowers }\end{array}$ & $\begin{array}{l}\text { The actual count when female flowers are } \\
\text { mature. }\end{array}$ \\
\hline 7 & $\begin{array}{l}\text { Number of male } \\
\text { flowers }\end{array}$ & $\begin{array}{l}\text { The actual count when male flowers are } \\
\text { mature. }\end{array}$ \\
\hline
\end{tabular}




\section{RESULTS}

Number of Days to Branching (forking) among Genotypes at Different Branching Levels

Analysis of variance (ANOVA) showed that the number of days to branching was highly significantly different $(\mathrm{P} \leq 0.01)$ among genotypes at branching level 1 and very highly significantly different $(\mathrm{P} \leq 0.001)$ at branching level 2,3 and 4 (Table 3).

Analysis on the mean number of days from planting to branching (forking) in cassava genotypes at different branching levels revealed that cassava genotype TME204 took the longest mean number of days to branching at all branching levels as compared to other genotypes used in this study. Conversely, genotype NASE12 took the shortest period in days to branching at all branching levels (Table 4).

\section{Number of Days from Branching to Visible Inflorescence Among Genotypes at Different Branching Levels}

The ANOVA showed a highly significant difference $(\mathrm{P} \leq 0.001)$ in number of days from branching to visible inflorescence at branching level 2. Similarly, at branching level 3, a significant differences $(\mathrm{P} \leq 0.05)$ was observed among the genotypes. However, no significant difference was observed among genotypes at branching level 1 and level $4(\mathrm{P} \geq 0.05)$ (Table 3).

The mean number of days from branching to visible inflorescences among genotypes at different branching level revealed that cassava genotype TME204 recorded the longest mean number of days to visible inflorescences at all branching levels (Table 5). However, there were no significant differences observed in number of days to inflorescences among cassava genotypes at branching level 3 for genotypes NASE2, NASE3, NASE9, NASE12, and NASE14.

\section{Number of Days for First Female Flower to Open After Branching Among Genotypes at Different Branching Levels}

ANOVA showed that at branching level 2, the number of days to the opening of first female flower were significantly different $(\mathrm{P} \leq 0.01)$ among genotypes. In contrast, no significant difference was observed at branching level 1,3 and $4(\mathrm{P} \geq 0.05)$ (Table 3). Furthermore, the results showed that among the

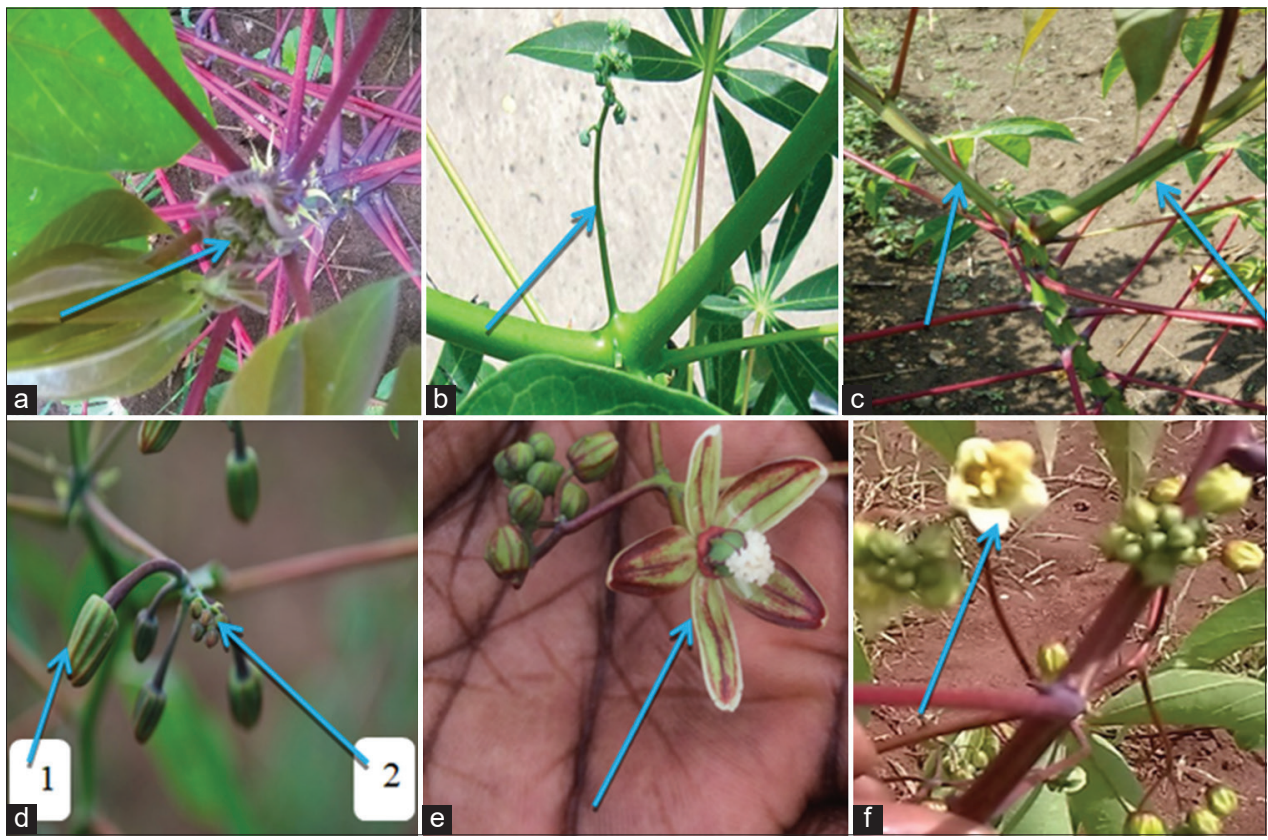

Figure 1: Cassava floral traits. (a) The first day forking is observed on plant, (b) Young cassava inflorescence (c) Branching habit, (d) 1. Cassava female flower, (d) 2. Cassava male flower, (e) Cassava female flower open and (f) Cassava male flower open

Table 3: Mean square of different traits studied

\begin{tabular}{|c|c|c|c|c|}
\hline \multirow[t]{2}{*}{ Traits } & \multicolumn{4}{|c|}{ MS Branching levels } \\
\hline & 1 & 2 & 3 & 4 \\
\hline \# days to $\mathrm{Br}$ & $1837.2 * *$ & $3088.2 * * *$ & $2037.6 * * *$ & $1150.73 * * *$ \\
\hline \#days from $\mathrm{Br}$ to visible If & $0.18^{\text {ns }}$ & $0.88 * * *$ & 0.55 * & $0.25^{\mathrm{ns}}$ \\
\hline \# days $1^{\text {st }}$ female flower open & $296.7^{\text {ns }}$ & $4.13 * *$ & $2.62^{\text {ns }}$ & $4.51^{\mathrm{ns}}$ \\
\hline \#days $1^{\text {st }}$ male flower open & $14.47^{\text {ns }}$ & $55.11^{\text {ns }}$ & $22.95^{\text {ns }}$ & - \\
\hline \# of male flower & $2288.9 * * *$ & $11591.4 * * *$ & $9721.5 * * *$ & $2844.4 * * *$ \\
\hline \# of female flower & $25.05 * *$ & $126.04 * *$ & $49.87^{*}$ & $12.5^{\mathrm{ns}}$ \\
\hline Branching habit & $0.36^{\mathrm{ns}}$ & $0.27 * *$ & $0.40 * * *$ & $0.27 *$ \\
\hline
\end{tabular}

\# = Number of $* * *, * *$ and $*$ significantly different at $\mathrm{P} \leq 0.001, \mathrm{P} \leq 0.01$ and $\mathrm{P} \leq 0.5$ respectively, $\mathrm{ns}=$ not significant, $\mathrm{Br}=\mathrm{Branching}, \mathrm{If}=$ Inflorescence, $\mathrm{MS}=$ mean square. $1=$ first branching level, $2=$ second branching level, $3=$ third branching level and $4=$ forth branching level 
cassava genotypes, genotype TME204 had the longest mean number of days to opening of the first female flower at branching level 1, with a mean of 38 days (Table 6). However, NASE3 took the shortest period of only 29 days. Similarly, at branching level 2, TME 204 had the longest mean number of days to have the first female flower open with mean of 34 days after branching, while NASE14 took the shortest period of a mean of 31 days. At branching level 3, there were no significant differences observed in number of days for the first female flower open for genotypes NASE14, NASE12 and NASE3. At branching level 4, NASE3 took the longest mean days to open the first female flower, with a mean of 35 days while NASE 12 took the shortest period with a mean of 32 days. NASE2 and NASE9 did not open flowers in any of the branching levels. No open flowers were observed in NASE 12 at branching levels 1

Table 4: Mean number of days to branching (forking) in cassava genotypes at different branching levels

\begin{tabular}{lcccc}
\hline Genotypes & \multicolumn{4}{c}{ Branching levels } \\
\cline { 2 - 5 } & 1 & 2 & 3 & 4 \\
\hline NASE12 & $125.1^{\mathrm{a}}$ & $150.6^{\mathrm{a}}$ & $176.5^{\mathrm{a}}$ & $208.4^{\mathrm{a}}$ \\
NASE2 & $143.0^{\mathrm{ab}}$ & $164.9^{\mathrm{ab}}$ & $194.0^{\mathrm{ab}}$ & $223.1^{\mathrm{ab}}$ \\
NASE9 & $146.7^{\mathrm{ab}}$ & $181.2^{\mathrm{bc}}$ & $212.8^{\mathrm{bc}}$ & $235.5^{\mathrm{bc}}$ \\
NASE14 & $152.3^{\mathrm{ab}}$ & $190.9^{\mathrm{c}}$ & $225.5^{\mathrm{c}}$ & $246.6^{\mathrm{c}}$ \\
NASE3 & $156.8^{\mathrm{b}}$ & $187.2^{\mathrm{c}}$ & $215.7^{\mathrm{c}}$ & $245.5^{\mathrm{c}}$ \\
TME204 & $199.2^{\mathrm{c}}$ & $244.4^{\mathrm{d}}$ & $272.3^{\mathrm{d}}$ & $302.0^{\mathrm{d}}$ \\
LSD $_{0.05}$ & $30.3^{\mathrm{n}}$ & 21.59 & 20.67 & 18.57 \\
\hline
\end{tabular}

Means followed by the same letter are not significantly different.

$1=$ first branching level, $2=$ second branching level, $3=$ third branching level and $4=$ forth branching level

Table 5: Mean number of days from branching to visible inflorescences among genotypes at different branching levels

\begin{tabular}{lcccc}
\hline Genotypes & \multicolumn{4}{c}{ Branching levels } \\
\cline { 2 - 5 } & 1 & 2 & 3 & 4 \\
\hline NASE12 & $6.609^{a}$ & $6.685^{a}$ & $6.796^{a b}$ & $7.129^{a}$ \\
NASE2 & $6.852^{a}$ & $6.238^{\mathrm{b}}$ & $6.746^{\mathrm{ab}}$ & $7.433^{\mathrm{a}}$ \\
NASE9 & $6.622^{\mathrm{a}}$ & $6.758^{\mathrm{a}}$ & $6.896^{\mathrm{ab}}$ & $7.335^{\mathrm{a}}$ \\
NASE14 & $6.909^{\mathrm{a}}$ & $6.896^{\mathrm{a}}$ & $7.204^{\mathrm{bc}}$ & $7.486^{\mathrm{a}}$ \\
NASE3 & $6.892^{\mathrm{a}}$ & $6.69^{\mathrm{a}}$ & $6.5^{\mathrm{a}}$ & $7.588^{\mathrm{a}}$ \\
TME204 & $7.284^{\mathrm{a}}$ & $7.871^{\mathrm{b}}$ & $7.722^{\mathrm{c}}$ & $8.429^{\mathrm{a}}$ \\
LSD $_{0.05}$ & 0.5422 & 0.3012 & 0.6229 & 1.342 \\
\hline
\end{tabular}

Means followed by the same letter are not significantly different,

$1=$ first branching level, $2=$ second branching level, $3=$ third branching level and $4=$ forth branching level

Table 6: Mean number of days to first female flower open among genotypes at different branching levels

\begin{tabular}{lcccc}
\hline Genotypes & \multicolumn{4}{c}{ Branching levels } \\
\cline { 2 - 5 } & 1 & 2 & 3 & 4 \\
\hline NASE12 & - & - & $32.9^{a}$ & $32.32^{\mathrm{a}}$ \\
NASE14 & $31.33^{\mathrm{a}}$ & $30.5^{\mathrm{a}}$ & $32.11^{\mathrm{a}}$ & $33.43^{\mathrm{a}}$ \\
NASE3 & $29.33^{\mathrm{a}}$ & $32.33^{\mathrm{bc}}$ & $33.98^{\mathrm{a}}$ & $35.3^{\mathrm{a}}$ \\
TME204 & $37.83^{\mathrm{a}}$ & $33.61^{\mathrm{d}}$ & - & - \\
LSD $_{0.05}$ & 46.43 & 0.496 & 3.000 & 55.40 \\
\hline
\end{tabular}

$(-)=$ No open flower observed, Means followed by the same letter are not significantly different between genotypes, $1=$ first branching level, $2=$ second branching and 2. TME 204 also did not open female flowers at branching levels 3 and 4 .

\section{Number of Days for First Male Flower to Open After Branching Among Genotypes at Different Branching Levels}

There was no significant difference on number of days to first male flower open at all branching levels among the cassava genotypes $(P \geq 0.05)$ (Table 3$)$. Mean number of days to first male flower open among genotypes at different branching level (Table 7) revealed that cassava genotype NASE3 had the longest mean number of days for first male flower to open after branching with a mean of 51 days, while

Table 7: Mean number of days to first male flower open among genotypes at different branching level

\begin{tabular}{lccc}
\hline Genotypes & \multicolumn{3}{c}{ Branching levels } \\
\cline { 2 - 4 } & 1 & 2 & 3 \\
\hline NASE12 & - & - & $50.2^{\mathrm{a}}$ \\
NASE14 & $46.36^{\mathrm{a}}$ & $47.27^{\mathrm{a}}$ & $56.09^{\mathrm{a}}$ \\
NASE3 & $50.64^{\mathrm{a}}$ & $50.87^{\mathrm{a}}$ & $50.25^{\mathrm{a}}$ \\
TME204 & $49.97^{\mathrm{a}}$ & $49.25^{\mathrm{a}}$ & - \\
LSD $_{0.05}$ & 14.27 & 5.660 & 11.54 \\
\hline
\end{tabular}

$(-)=$ No open flower observed, branching level 4 did not show any open flowers, Means with the same letter (a) are not significantly different, $1=$ first branching level, $2=$ second branching level and $3=$ third branching level

Table 8: Mean number of male flowers among genotypes at different branching level

\begin{tabular}{lcccc}
\hline Genotypes & \multicolumn{4}{c}{ Branching levels } \\
\cline { 2 - 5 } & 1 & 2 & 3 & 4 \\
\hline NASE12 & $0.26^{\mathrm{a}}$ & $5.07^{\mathrm{a}}$ & $29.16^{\mathrm{a}}$ & $43.71^{\mathrm{b}}$ \\
NASE2 & $68.67^{\mathrm{b}}$ & $168.33^{\mathrm{d}}$ & $164.87^{\mathrm{d}}$ & $113.35^{\mathrm{d}}$ \\
NASE9 & $8.08^{\mathrm{a}}$ & $23.09^{\mathrm{ab}}$ & $38.34^{\mathrm{ab}}$ & $35.49^{\mathrm{ab}}$ \\
NASE14 & $7.67^{\mathrm{a}}$ & $73.84^{\mathrm{bc}}$ & $95.04^{\mathrm{c}}$ & $79.98^{\mathrm{c}}$ \\
NASE3 & $39.09^{\mathrm{b}}$ & $77.89^{\mathrm{c}}$ & $85.7^{\mathrm{bc}}$ & $71.67^{\mathrm{c}}$ \\
TME204 & $0.76^{\mathrm{a}}$ & $8.1^{\mathrm{a}}$ & $9.5^{\mathrm{a}}$ & $12.44^{\mathrm{a}}$ \\
LSD $_{0.05}$ & 25.09 & 52.80 & 51.01 & 38.48 \\
\hline
\end{tabular}

Means followed by the same letter are not significantly different, $1=$ first branching level, $2=$ second branching level, $3=$ third branching level and $4=$ forth branching level

Table 9: Mean number of female flowers among genotypes at different branching levels

\begin{tabular}{lcccc}
\hline Genotype & \multicolumn{4}{c}{ Branching levels } \\
\cline { 2 - 5 } & 1 & 2 & 3 & 4 \\
\hline NASE12 & $0^{\mathrm{a}}$ & $0.158^{\mathrm{a}}$ & $1.605^{\mathrm{a}}$ & $3.359^{\mathrm{a}}$ \\
NASE2 & $5.508^{\mathrm{b}}$ & $16.524^{\mathrm{c}}$ & $7.016^{\mathrm{ab}}$ & $4.686^{\mathrm{a}}$ \\
NASE9 & $0.146^{\mathrm{a}}$ & $1.002^{\mathrm{a}}$ & $3.08^{\mathrm{a}}$ & $2.318^{\mathrm{a}}$ \\
NASE14 & $0.105^{\mathrm{a}}$ & $4.367^{\mathrm{ab}}$ & $6.73^{\mathrm{ab}}$ & $4.22^{\mathrm{a}}$ \\
NASE3 & $5.861^{\mathrm{b}}$ & $9.802^{\mathrm{bc}}$ & $11.968^{\mathrm{b}}$ & $7.503^{\mathrm{a}}$ \\
TME204 & $0.125^{\mathrm{a}}$ & $1.029^{\mathrm{a}}$ & $1.417^{\mathrm{a}}$ & $0^{\mathrm{a}}$ \\
LSD $_{0.05}$ & 1.489 & 7.377 & 6.232 & 7.519 \\
\hline
\end{tabular}

Means followed by the same letter are not significantly different, $1=$ first branching level, $2=$ second branching level, $3=$ third branching level, and $4=$ forth branching level 
NASE14 recorded shorter periods with a mean of 46 days after branching at branching level 1. Similarly, NASE3 showed the longest days to first male open at branching level 2 with a mean of 51 days after branching while NASE14 recorded the shortest period with mean of 47 days after branching. At branching level 3, the longest mean was observed in NASE14 with a mean of 56 days after branching while the shortest mean was 50 days after branching observed in genotype NASE12. However, NASE2 and NASE9 did not show any open male flowers in any of the branching levels. NASE12 only showed open male flowers at branching level 3. Genotype TME204 did not show open male flower at branching level 3. Branching level 4 did not show any open flower for all genotypes (Table 7).

\section{Number of Male Flowers Among Genotypes at Different Branching Levels}

Results for the number of male flowers among genotypes at different branching level showed a highly significant variation among the genotypes in all branching levels $(\mathrm{P}<0.001)$ (Table 3). The mean number of male flowers produced per branching level showed that genotype NASE2 had the highest mean number of male flowers in all branching levels as compared to other genotypes used in this study (Table 8). This genotype recorded a mean of 69 male flowers at branching level 1, 169 male flowers at branching level 2, 165 male flowers at branching level 3 and 113 male flowers at branching level 4. In contrast, TME204 recorded the lowest mean number of male flowers in all branching levels among genotypes.

\section{Number of Female Flowers Among Genotypes at Different Branching Levels}

Results for female flowers produced among genotypes showed a significant difference at branching levels $1,2(\mathrm{P} \leq 0.01)$ and at branching level 3 ( $\mathrm{P} \leq 0.05)$, However, there were no significant differences among genotypes at branching level $4(\mathrm{P} \geq 0.05)$ (Table 3). The mean number of female flowers among genotypes at different branching levels revealed that at branching level 1, NASE3 and NASE2 had the highest female flowers both with a mean of 6 flowers while NASE12 did not produce any flower at branching level 1 (Table 9). At branching level 2 NASE2 recorded the highest mean of 17 flowers while NASE12 did

Table 10: Mean number of branching habit among genotypes at different branching levels

\begin{tabular}{lcccc}
\hline Genotypes & \multicolumn{4}{c}{ Branching levels } \\
\cline { 2 - 5 } & 1 & 2 & 3 & 4 \\
\hline NASE12 & $2.078^{\mathrm{a}}$ & $2.099^{\mathrm{a}}$ & $2.045^{\mathrm{b}}$ & $2.028^{\mathrm{b}}$ \\
NASE2 & $2.657^{\mathrm{a}}$ & $2.714^{\mathrm{bc}}$ & $2.81^{\mathrm{a}}$ & $2.809^{\mathrm{a}}$ \\
NASE9 & $2.137^{\mathrm{a}}$ & $2.406^{\mathrm{ab}}$ & $2.479^{\mathrm{b}}$ & $2.55^{\mathrm{a}}$ \\
NASE14 & $2.735^{\mathrm{a}}$ & $2.753^{\mathrm{bc}}$ & $2.87^{\mathrm{a}}$ & $2.809^{\mathrm{a}}$ \\
NASE3 & $2.85^{\mathrm{a}}$ & $2.802^{\mathrm{c}}$ & $2.952^{\mathrm{a}}$ & $2.805^{\mathrm{a}}$ \\
TME204 & $2.833^{\mathrm{a}}$ & $2.895^{\mathrm{c}}$ & $3^{\mathrm{a}}$ & $2.512^{\mathrm{a}}$ \\
LSD $_{0.05}$ & 0.8126 & 0.3864 & 0.2629 & 0.4563 \\
\hline
\end{tabular}

Means followed by the same letter are not significantly different, $1=$ first branching level, $2=$ second branching level, $3=$ third branching level and $4=$ forth branching level not flower. At branching level 3 NASE3 recorded the highest mean number of female flowers with mean of 12 flowers and NASE12 recorded the lowest mean of 2 flowers. At branching level 4 NASE3 produced the highest mean number with a mean of 8 flowers while TME204 did not produce any flower.

\section{Branching Habit Among Genotypes at Different Branching Levels}

ANOVA results for number of branching habit showed significant differences among genotypes at branching level 2 , $\mathrm{P} \leq 0.01$, branching level $3, \mathrm{P} \leq 0.001$ and branching level 4 , $\mathrm{P} \leq 0.05$. No significant difference was observed at branching level 1 (table 3). Moreover, the means of branching habit among genotypes for different branching levels is shown in Table 10. The highest number of branching habit produced was observed in genotypes NASE3, NASE14 NASE2 and TME204 which recorded the mean of 3 branching habit. NASE12 and NASE9 recorded a mean of 2 branching habit in all branching levels except NASE9 which showed the mean of 3 branching habit at branching level 4 .

\section{DISCUSSION}

The objective of this study was to find the possible solution to cassava flowering problems. The output from this research directly contributes to cassava genetic improvement through plant breeding. Indeed, synchronization of flowering time is still a difficult issue in cassava breeding [14]. Non-synchronized flowering can result to inability to use cassava genotypes in breeding programs [15]. Researchers have observed that in some cassava varieties, flowering can begin as early as six weeks after planting while in others it may occur after 10 months after planting [16]. All the cassava genotypes used in this study exhibited some ability to flower under the prevailing climatic conditions at $\mathrm{NaCRRI}$ although there were individual differences. Similar observation was reported by other researchers who found large differences in ability of cassava genotypes to flower [17].

This study identified big differences among genotypes across branching levels in the number of days to branching of approximately three months. Result revealed that in the genotypes studied, branching started after four months to six months after planting (Table 4). Indeed, this result supported earlier reports on the number of days to branching (forking) which reported that some clones start to branch or fork at two months after planting while others start branching at six months after planting [10]. This suggests that delayed planting of the early branching genotypes when used as female parent will be necessary for crossing.

Very young inflorescences were observed at the branching point within one week after branching. Early research reported similar result revealing that young inflorescence of cassava is usually observed at the branching point within one week of branching [10]. This study identified that differences in time among genotypes from branching to a visible inflorescence was 
not larger than one and a half day. It was observed this difference would not be a factor for synchronization.

The number of female flowers was generally low in all genotypes at different branching levels and most male and female flowers aborted before full flower development in some genotypes. This suggests that applying techniques such as growth regulators, red light and finding the most optimal locations for flowering can be useful for the purpose of enhancing flowering among genotypes. The large numbers of male flowers produced in all genotypes studied confirm the observation made by other authors [18] who reported that male flowers of cassava usually outnumber the female flowers. Moreover, other research work [9] had pointed out that in a manual pollination program, on the average, only one male flower is needed to pollinate three to five female flowers. This suggests that male flower production may not be a limiting factor to hybrid seed production under manual and open pollination systems in the cassava genotypes studied, except TME204 at all branching levels and NASE12 at branching levels 1 and 2 .

Indeed, in all genotypes, mature male and female flowers opened except NASE2 and NASE9 that did not show any male or female flower open. Similar results have been identified and reported earlier [19] which indicated that in some cassava lines, the flowers rarely open when being pollinated under natural conditions. The numbers of days to first female flower open and number of days to first male flower open among genotypes supported the observation made in earlier work [10], which reported that male flower open 20 to 30 days later after female flowers open. On this ground, there is a need to delay the planting of the early flowering genotypes when used as female parent.

It is evident that inflorescence follows branching in cassava. Therefore, highly branched genotypes have more flowers per plant than those with fewer branches. This study showed that branching habit among genotypes studied varied from dichotomous to trichotomous. These results are supported previous work which reported that branching habit in cassava varied and can be dichotomous, trichotomous or tetrachotomous [13]. With regard to this, cassava genotypes with low branching habit can also be treated with plant growth regulators, red light and finding the most optimal locations for flowering to enhance flowering.

\section{CONCLUSION}

Number of days to branching generally varied among all the genotypes studied, therefore delaying planting for the early genotypes when used as female parent will be necessary for crossing. After branching, cassava took 6 to 8 days to show inflorescence and this difference is not significant to be a factor for synchronization. Male flowers produced per branch were adequate in all genotypes studied; therefore obtaining pollen for crosses does not seem to be a limiting factor. However, female flowers that are produced per branch generally were few in all genotypes and most of them were produced in branching levels 2 and 3. This calls for other strategies like application of growth regulators to enhance flowering. Female flowers opened between 30-38 days after branching and males took 50 to 56 days on the same branch, therefore there is a possibility to delay planting of the early flowering genotypes when used as female parent.

\section{Recommendation}

The late flowering genotypes like genotype TME204 have to be planted earlier by approximately two months ahead of the early flowering genotypes. Branching levels 2 and level 3 which have the most female flowers in all genotypes studied should be used for crossing. Applying techniques such as growth regulators, red light and finding the most optimal locations for flowering is recommended for further study as a way to enhance flowering among genotypes.

\section{ACKNOWLEDGEMENT}

The authors are grateful to National Crops Resources Research Institute, Uganda and Makerere University, Uganda for provision of study materials and supervision of this research. This research was funded by NextGen Cassava Breeding Project.

\section{REFERENCES}

1. Nassar, N. M. A. Cytogenetics and evolution of cassava (Manihot esculenta Crantz). Genetics and Molecular Biology, 2000; 23 (4), p.1003-1014.

2. Akinbo, O., Labuschagne, M. and Fregene, M. Embryo rescue as a method to develop and multiply a backcross population of cassava (Manihot esculenta Crantz) from an interspecific cross of Manihot esculenta ssp. flabellifolia. African Journal of Biotechnology, 2010; 9(42), p. 7058-7062

3. Food and Agriculture Organization. Production year book, FAO, 2006; http://www.fao.org/3/a-i3278e.pdf

4. Ceballos, H., Iglesias, C. A., Perez, J. C. and Alfred, G. O. D. Cassava breeding : opportunities and challenges. Plant Molecular Biology, 2004; 56, p.503-516.

5. Mezzalira, I., Costa, C. J., Vieira, E. A., Freitas, J. D., Silva, M. S., Denke, M. L. and Nascimento, K. Pre-germination treatments and storage of cassava seeds and their correlation with emergence of seedlings. Journal of Seed Science, 2013; 35 (1), p.113-118.

6. Yakasai, M. Economic Contribution of Cassava Production (A case Study of Kuje Area Council Federal Capital Territory, Abuja, Nigeria). Bayero Journal of Pure and Applied Sciences, 2010; 3 (1), p.215-219.

7. Akinngbe, O. Constraints and Straegies Towards Improving Cassava Production And Processing In North Agricultural Zone of Enugu State, Nigeria. Bangladesh Journal of Agricultural Research ., 2010; 35 (3), p.387-394.

8. Nwaogu, L. A., Agha, N. C. and Alisi, C. S. Investigation on the effect of cassava effluent-polluted soil on germination, emergence and oxidative stress parameters of Telferia occidentalis. Journal of Biodivesty and Environmental Sciense, 2011; 1 (6), p.104-111.

9. Fukuda, M. G., De Oliveira, S. and Iglesias, C. Cassava Breeding Crop Breeding and Applied Biotechnology, 2002; 2 (4), 617-638.

10. Halsey, M. E., Olsen, K. M., Nigel J, T. and Paul, C.A. (2008). Reproductive biology of cassava (Manihot esculenta Crantz) and isolation of experimental field trials. Crop Science, 2008; 48, 49-58.

11. Jennings, D. L. and Iglesias. Cassava Biology, Production and Utillization, Breeding for Crop Improvement, 2002; p.149-166.

12. Chavarriaga, P. A. and Halsey, M. Cassava (Manihot esculenta Crantz ): Reproductive biology and practices for confinement of experimental field trials. Presented in program for biosaftysystems international food policy research institute, 2008.

13. Alves, A. A. C. Cassava Botany and Physiology. In: Hillocks, R. J., 
Bellotti, M. J. and Thresh, A. C. (eds.), Cassava Biology,Production and Utilisation, Bahia, Brazil: CABI International, 2002; 67-89.

14. Mulualem, T. and Bekeko, Z. Assessment of Conventional Breeding on Cassava and its Physiological Adaptive Mechanisms: Implication for Moisture Stress. Asian Journal of Agricultural Research, 2015; 9 (2), p.38-54.

15. Davies, S., Tohme, J. and Fregene, M. Modification of flowering in cassava, 2008. http:// africancrops.net accessed.

16. Lebot, V. Tropical Root and Tuber Crops: Cassava, Sweet Potato, Yams, and Aroids. Crop Production Science in Horticulture Series,
2009; 17, p.1-433

17. Nunekpeku, W., Amoatey, H. M., Oduro, V., Klu, G. Y. P. and Danso, K. E. Study of the Reproductive Characteristics of Nine Cassava Accessions. West African Jounrnal of Applied Ecology, 2013; 21 135-143.

18. Kawano. Cassava. Hybridiza- tion of crop plants. Fehr WR, Handley HH, eds. Madison, WI: American Society of Agronomy Crop Science, 1980; p.225-233

19. Hahn, S., Bai, V. and Asiedu, R. Spontaneous somatic tetraploids in cassava. Japanese Journal of Breeding, 1992; 42, p.303-308. 